pluses can contribute to the development of agriculture in such countries if they are used as a stock of capital to be drawn on while important agricultural reforms are undertaken, and to enable idle labour to be put to work without causing inflation. Indeed, a pledging session in New York on September 5 for the United Nations World Food Programme was aimed at raising a fund of 100 million dollars in surplus agricultural products and cash for development, and Earl de la Warr's address should remove any hesitation which the British Government had in pledging 5 million dollars to the programme.

Earl de la Warr concluded by expressing the hope that the United Kingdom would play a worthy part in this great international attack on hunger, which, as he observed, is essentially an extension into wider fields of work that has been done for generations by Britain's own Colonial agricultural and other Services in areas for which Britain has been responsible. The recurrent emphasis at successive British Association meetings in recent years on the interest, the opportunities and the responsibilities of the scientist in the under-developed territories is as welcome as it is timely. Its expression at these meetings should encourage scientists generally to make their full contribution to technical assistance, to overseas research and in educational work, for example, and not least when, in spite of the establishment of the Department of Technical Co-operation, Government support seems somewhat lukewarm. The British Association meeting has undoubtedly displayed some opportunities for specific action by scientists themselves, though it probably remains true that in the broadest sense the organization of overseas research generally and the revitalizing and effective use of the Overseas Research Council are still among the most important.

\section{DIFFUSE X-RAY REFLEXIONS FROM CRYSTALS}

Diffuse X-ray Reflections from Crystals

By Dr. W. A. Wooster. Pp. xi +200 . (Oxford: Clarendon Press; London: Oxford University Press, 1962.) 35s. net.

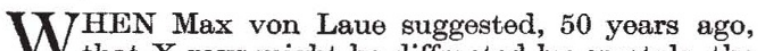
that X-rays might be diffracted by crystals, the physicists of his day were doubtful whether any observable pattern would be obtained because of the thermal vibrations of the atoms which might, they thought, smear out the diffraction spectra. However, the experiment was tried, and it succeeded so well that the question of thermal vibration effects became of secondary importance except in so far as it was interesting to study them through the temperaturesensitive diminution of Bragg intensity that they caused. The idea that there should be a definite pattern of diffuse scattering due to thermal vibration which would depend on crystal orientation (contrary to early Debye theory) was raised by Faxén and Waller in 1923, but so few crystallographers read these mathematical papers that even when the patterns were found on well-exposed Laue photographs taken with the whole radiation from copper targets (see, for example, Proc. Roy. Soc., A, 125, plate 11, Fig. 6, opposite p. $674(1929))$ they were not recognized. They were in fact repeatedly seen and ignored until about 1938-39, when they were actively looked for by Laval in France and independently noted by Wadlund in the United States and Preston in Great Britain. The whole story, of which this is the briefest outline, is an amusing commentary on the 'two cultures' that can exist even within a most specialized corner of a specialized discipline when experimentalist and mathematician are unaware of each other's work.

Nowadays every X-ray crystallographer has to be familiar with the use of mathematical tools. The short statement on the inside paper cover of Dr. Wooster's book claims that "This book has been written with a minimum of mathematical analysis". Well, that may be so; but the "young research student" for whom the book is intended had better glance through it before he derives any comfort from that assurance. There is an index of symbols that runs to more than six pages with about thirty definitions on each page.

Dr. Wooster is an authority in the field and an experienced writer and teacher. Moreover, this is the first book of its kind, and it is bound, therefore, to find an honoured place in the crystallographer's library. But one cannot help regretting that the author has so deliberately restricted his treatment of the subject. He gives a general survey of the theoretical basis of diffuse scattering and of the experimental methods by which it has been observed; then adds a chapter on the determination of elastic constants from diffuse scattering, and one on the determination of the elastic frequency spectrum. Useful chapters follow on diffuse scattering due to structural imperfections and on that from molecular crystals, but there is no mention of zero-point energy, of diffuse effects due to radiation damage or of the ways in which these various effects may be sorted out experimentally. Electron and neutron diffraction effects have also been deliberately excluded, probably because the author would rather not deal with them unless he can do so exhaustively. But sometimes a brief outline may be better than nothing at all.

There are good indexes, but also several misprints and some errors. KATHLEEN LONSDALE

\section{NUCLEAR REACTOR PHYSICS}

\section{Reactors}

Vol. 2. Edited by H. R. McK. Ryder. (Progress in Nuclear Energy, Series 2.) Pp. vi $+557+$ xii. (London and New York: Pergamon Press, 1961.) 105s. net.

CINCE the extensive declassification of work on $S$ the civil applications of nuclear power in the early 1950 's, it has become difficult to keep up with the very large numbers of papers and reports being published in this field. The review series Progress of Nuclear Energy was therefore warmly welcomed when it was founded by Pergamon Press in 1955. The series is now divided into 12 sections, the volume under consideration being the second volume in the Reactors section.

The present book is based entirely on material presented at the 1958 United Nations Geneva Conference on the Peaceful Uses of Atomic Energy, and contains 16 papers of which ten are on reactor physics, and six are rather more general papers on specific 